Leeds Regional Hospital Board. We appreciated the help given by Sister Cox.

\section{References}

Barnett, C. H., and Cobbold, A. F. (1962). Fournal of Bone and foint Surgery, 44B, 662 .

Chandler, G. N., and Wright, V. (1958). Lancet, 2, 659.

Charnley, J. (1960). Triangle, 4, 175.

Corbett, M., Seifert, M. H., Hacking, C., and Webb, S. (1970). British Medical fournal, 1, 24.

Dintenfass, L. (1963). Journal of Bone and foint Surgery, 45A, 1241.

Dowson, D., Longfield, M. D., Walker, P. S., and Wright, V. (1968). Proceedings of the Institution of Mechanical Engineers, 182, 3N, 70.
Goddard, R., Dowson, D., Longfield, M. D., and Wright, V. (1969). In Lubrication and Wear in foints, ed. V. Wright, p. 134. Sector Press. Helal, B. (1970). British Medical fournal, i, 50

Helal, B., and Karadi, B. S. (1968). Annals of Physical Medicine, 9, 334.

Jacobsen, M. (1965). British fournal of Psychiatry, 111, 545.

McCutchen, C. W. (1959). Nature, 184, 1284.

Maroudas, A. (1967). Proceedings of the Institution of Mechanical Engineers, $181,3 \mathrm{~J}, 122$.

Nuki, G., Ferguson, J., Boyle, J. A., and Boddy, K. (1969). Nature, 224, 1118 .

Seller, P. C., Dowson, D., Longfield, M. D., and Wright, V. (1969). In

Lubrication and Wear in foints, ed. V. Wright, p. 142. Sector Press.

Shah, K. D., and Wright, V. (1967). Annals of the Rheumatic Diseases, 26, 316.

Tanner, R. I. (1966). Physics in Medicine and Biology, 11, 119.

\title{
Smoking, Chronic Bronchitis, and Lung Cancer
}

\section{J. RIMINGTON}

British Medical fournal, 1971, 2, 373-375

\section{Summary}

A follow-up was carried out on 21,579 male mass radiography volunteers aged at least 40 who had been the subject of an earlier investigation in which their smoking habits and sputum production were recorded and the prevalence of lung cancer was determined after chest $x$-ray examination. During the follow-up period, which was a minimum of 36 months and a maximum of 56 months, 64 new cases of lung cancer were identified by cross checking records with the registers of the regional cancer registration bureau. A significantly higher incidence of lung cancer was found in those with chronic bronchitis than in those without this disease. In the smoking categories, cigarette smokers with chronic bronchitis had a higher incidence than those without it, and this relationship was maintained irrespective of age and amount smoked. It is concluded that persons who smoke run a higher risk of chronic bronchitis than non-smokers and those who develop bronchitis run a higher risk of developing lung cancer.

\section{Introduction}

An earlier article (Rimington, 1968a) described how, during 1964 and 1965, the smoking habits and sputum histories of 21,579 male mass radiography examinees were taken before $x$-ray examination, the object being to find and compare the lung cancer rates of those reporting and of those not reporting sputum on most days for at least five years.

Some details of the article will provide continuity with the present study:

The examinees, who came from the part of Cheshire within the Manchester Hospital Region, were volunteers, either from industry or general public and were aged at least 40 . Their smoking habits were similar to those found in a nationwide study by Todd (1966) except for a moderate bias to pipe smokers and non-smokers. Twelve per cent. $(2,716)$ reported sputum on most days for at least five years and there was a marked gradient in the percentage reporting this with increasing cigarette consumption. Thirty-three lung cancers were found, all in past or present smokers. Irrespective of the smoking category, the rates of lung cancer were much higher in those reporting than in those not reporting daily sputum

\section{St. Thomas' Hospital, Stockport SK3 8BL}

J. RIMINGTON, M.D., Medical Director, Mass Radiography ServiceSouthern Division, Manchester Regional Hospital Board for a minimum of five years. Cigarette smokers in these two groups had rates of 5.09 and $1.30 / 1,000$ respectively, and this difference was found to be statistically significant $(P<0.01)$. A similar relationship was maintained irrespective of the amount smoked. Moreover, the lung cancer rates for histologically proved cancers maintained the same relationship.

It was considered that the data were reliable and that the selection of a minimum period of five years for the duration of the sputum production made it unlikely that lung cancer could be the cause of the sputum. Furthermore, it was shown later (Rimington, 1968b) that differences in the age distribution of the volunteers did not account for the differences in prevalence of lung cancer between those reporting and those not reporting daily sputum for a minimum of five years.

It was concluded that the study, taken in conjunction with evidence of other investigations using data derived by different selective processes, confirmed a positive association between chronic bronchitis, as defined on the basis of persistent sputum production for a number of years in the absence of other causative disease, and lung cancer.

The present article gives the results of a follow-up of the original volunteers with particular regard to the lung cancer incidence among those with and those without chronic bronchitis.

\section{Methods}

The identification of new cases of lung cancer arising in the volunteers during the years subsequent to the initial examinations was made possible by the co-operation of the director and staff of the Manchester Regional Cancer Registration Bureau. Cases of malignancy are reported to the bureau by doctors and hospital authorities and, in addition, by the General Register Office when a death certificate refers to malignant disease and the deceased lived in the Manchester Regional Hospital Board's area. So far as the latter category is concerned, the bureau obtains more detailed information from local sources and registers such cases under the year in which the disease was first brought to light.

The volunteers' records were checked against each year's registrations from 1964 to, and including, 1968. The minimum and maximum period of follow-up was 36 and 56 months respectively. A year's registrations were not checked until at least 18 months had passed after the end of the particular year, and this delay meant that most of the late notifications via the General Register Office had been included on the registers because lung cancer, in the absence of treatment, is usually fatal within that period. 


\section{Results}

In all, 64 new cases of lung cancer were found, and their distribution is given in the Table. As regards the actual incidence of the disease, it will be noted that it is negligible for nonsmokers, moderate for ex-smokers and pipe-smokers, but greater for cigarette smokers, rising with increased consumption.

The lung cancer incidence is higher in those with chronic bronchitis $(5.89 / 1,000)$ than in those without this condition $(2 \cdot 54 / 1,000)$, the difference being highly significant statistically $(P<0.01)$. Cigarette smokers with chronic bronchitis have almost twice the incidence $(7 \cdot 12 / 1,000)$ of cigarette smokers without bronchitis $(3.61 / 1,000)$ and this difference is statistically significant but at the conventional level $(P<0.05)$. Most of the ex-smokers had previously smoked cigarettes, and those with chronic bronchitis have a higher lung cancer incidence than those without it. The position is, however, reversed for nonsmokers and pipe smokers but the differences are very small and are not statistically significant.

It is well known that both productive cough and lung cancer are associated with smoking and it is therefore possible that the high rate of lung cancer among the cigarette smokers with chronic bronchitis is simply due to the association of both conditions with cigarette smoking. In view of this possibility the cigarette smokers have been divided into three consumption categories-light, medium, and heavy-but, irrespective of the amount smoked, the lung cancer incidence of those with chronic bronchitis is higher than those without this disease.

Another possible cause of the higher lung cancer incidence in those with chronic bronchitis could be the age distribution of the sample, because chronic bronchitis is reported more often by older individuals (Palmer, 1954; Oswald and Medvei, 1955; College of General Practitioners, 1961; Rimington, 1969), among whom the prevalence of lung cancer is greater. Because of this, the lung cancer incidence in each consumption category has been standardized for age by basing it on a population equally distributed over five-year age groups and these rates are given in the Table. It will be noted that they maintain the same relationship in regard to the bronchitic status of the volunteers as do the actual rates. It would seem, therefore, that differences in lung cancer incidence between those with and those without chronic bronchitis are not caused by differences of age distribution.

The results for the 39 cases of lung cancer confirmed histologically are not shown here but the relationship of a higher incidence in the chronic bronchitics as compared with the non-bronchitics is maintained.

\section{Discussion}

The reliability of the data and the validity of the findings of the original investigation (Rimington, 1968a) were fully discussed then, and since the present study uses much of the original basic data and since the findings are similar it seems unnecessary to cover the same ground again. However, the method of follow-up and the possibility of case loss does need further consideration.

A follow-up in respect of the lung cancer incidence could be complete only if a necropsy was done for each death and a chest $x$-ray film taken for each survivor at the end of the followup period. Consequently, though the use of cancer registration is a readily available and easy means of identifying lung cancer cases among the volunteers, it cannot be claimed to have given a complete follow-up. Known cases of lung cancer are not always notified by doctors and hospitals; possibly, private patients feature largely among these. Cases with rapidly progressing disease or those with chronic bronchitic symptoms masking the symptoms of an underlying cancer may be misdiagnosed and, consequently, escape registration. However, the late notifications via death certificates probably correct the losses in respect of diagnosed disease. Losses through misdiagnosis remain and could influence the results, though in what direction can only be a matter for speculation.

One definite source of case loss is emigration from Cheshire to other areas of the country and migration within the county. It is possible to calculate a figure of $28 / 1,000$ as the maximum annual loss of males aged 45 and over in the county from emigration and migration within the county (General Register Office, 1968). This figure allows for the exclusion of migrants within the areas of county boroughs, municipal boroughs, and urban and rural districts because these would not actually be lost from the Cheshire part of the Manchester Hospital Region. Applying this figure for Cheshire County as a whole to the area with which we are concerned would produce a loss of volunteers sufficient to cause a deficiency of five lung cancer cases, at the rate of lung cancer found among the volunteers during the follow-up period. Even if all the cancer cases were non-bronchitics their inclusion would not upset the significance of the findings given in the Table.

The number of cancer cases found during the follow-up is lower than expected from 21,579 middle-aged or elderly men. However, this is partly due to the age distribution of the volunteers-two-thirds were under 55 and only $17 \%$ over 60 . Furthermore, having been screened, the volunteers' incidence of lung cancer is apt to be lower than normal in the year or so immediately after the examinations. This is also suggested by the fact that 33 lung cancers were found on initial examination while the follow-up produced very few in 1965 but more each year until 1968 when 25 were identified. Finally, though it is impossible to be certain that the volunteers were representative of the population of the geographical area in which they lived, they were drawn from practically every town and district within that area, and to some extent they will reflect the lung cancer incidence of that area. In fact, the average annual lung cancer incidence of each five-year age group of the volunteers during the period of follow-up was much the same as the corresponding rate for the male population of the Cheshire part of the Manchester Hospital Board Region as calculated from the registrations of the Regional Cancer Bureau during the same period. The part of Cheshire concerned has an appreciable number of towns of under 50,000 inhabitants and many rural districts, and the lung cancer incidence is recognized to be lower than average in such areas.

Incidence of Lung Cancer per Thousand Male Volunteers Aged 40 or more by Smoking Habits and Sputum History, during a Follow-up Period of 36 Months Minimum and 56 Months Maximum. ( $S$ denotes persons claiming daily sputum for 5 years. NS denotes those not claiming this symptom)

\begin{tabular}{|c|c|c|c|c|c|c|c|c|c|c|c|c|c|c|c|c|c|}
\hline & & \multirow{2}{*}{\multicolumn{2}{|c|}{ Non-smokers }} & \multicolumn{8}{|c|}{ Cigarette Smokers } & \multirow{2}{*}{\multicolumn{2}{|c|}{ Ex-smokers }} & \multirow{2}{*}{\multicolumn{2}{|c|}{ Pipe Smokers }} & \multirow{2}{*}{\multicolumn{2}{|c|}{ All Subjects }} \\
\hline & & & & \multicolumn{2}{|c|}{$1-9$} & \multicolumn{2}{|c|}{$10-19$} & \multicolumn{2}{|c|}{$20+$} & \multicolumn{2}{|c|}{ All } & & & & & & \\
\hline & & NS & $\mathbf{s}$ & NS & $\mathbf{S}$ & NS & $\mathbf{s}$ & NS & $\mathbf{s}$ & NS & $\mathbf{s}$ & NS & $\mathbf{s}$ & NS & $\mathbf{s}$ & NS & $\mathbf{s}$ \\
\hline \multirow[t]{2}{*}{$\begin{array}{l}\text { No. of subjects } \\
\text { No. of cases } . . \\
\text { Actual incidence }\end{array}$} & \multirow[t]{2}{*}{$\because$} & \multirow[t]{2}{*}{$\begin{array}{r}2,723 \\
1 \\
0.37\end{array}$} & \multirow[t]{3}{*}{$\begin{array}{r}139 \\
0\end{array}$} & \multirow[t]{2}{*}{$\begin{array}{r}1,319 \\
3 \\
2 \cdot 27\end{array}$} & \multirow[t]{2}{*}{$\begin{array}{r}160 \\
1 \\
6 \cdot 25\end{array}$} & \multirow[t]{2}{*}{$\begin{array}{r}4,380 \\
13 \\
2.97\end{array}$} & \multirow[t]{2}{*}{$\begin{array}{r}806 \\
6 \\
7 \cdot 44\end{array}$} & \multirow[t]{2}{*}{$\begin{array}{r}4,271 \\
20 \\
4 \cdot 68\end{array}$} & \multirow[t]{2}{*}{$\begin{array}{r}998 \\
7 \\
7.01\end{array}$} & $\begin{array}{r}9,970 \\
36 \\
3.61\end{array}$ & $\begin{array}{r}1,964 \\
14 \\
7 \cdot 12 \\
\end{array}$ & \multirow[t]{2}{*}{$\begin{array}{r}4,121 \\
6 \\
1.45\end{array}$} & \multirow[t]{2}{*}{$\begin{array}{r}395 \\
2 \\
5.06\end{array}$} & \multirow[t]{2}{*}{$\begin{array}{r}2,049 \\
5 \\
2.43\end{array}$} & \multirow[t]{3}{*}{$\begin{array}{r}218 \\
0\end{array}$} & $\begin{array}{r}18,863 \\
48 \\
2.54\end{array}$ & $\begin{array}{r}2,716 \\
16 \\
5 \cdot 89\end{array}$ \\
\hline & & & & & & & & & & \multicolumn{2}{|c|}{$0.02<P<0.05$} & & & & & \multicolumn{2}{|c|}{$0.001<\mathrm{P}<0.01$} \\
\hline $\begin{array}{c}\text { Age standardized } \\
\text { incidence }\end{array}$ & .. & $1 \cdot 19$ & & 2.06 & $4 \cdot 63$ & $4 \cdot 31$ & $7 \cdot 85$ & $8 \cdot 55$ & $12 \cdot 18$ & $5 \cdot 22$ & $9 \cdot 09$ & 1.99 & 3.97 & $3 \cdot 30$ & & 3.58 & $6 \cdot 44$ \\
\hline
\end{tabular}




\section{Conclusions}

This study has shown that there is a higher incidence of lung cancer among mass radiography volunteers with chronic bronchitis than among those without this disease. The findings of the original prevalence study (Rimington, 1968a), that chronic bronchitics who smoke cigarettes run an especially high risk of lung cancer, is confirmed.

Another investigation (Rimington, 1969) among a larger group of mass radiography volunteers from whom the volunteers considered here were drawn has shown that those who smoke tobacco, and especially cigarettes, have a significantly greater risk of developing chronic bronchitis than non-smokers. Moreover, the findings suggested that tobacco smoking was of far greater importance than the other factors normally accepted as contributing to the development of chronic bronchitis-for example, air pollution, respiratory infections, dusty work, lower social class, etc.

The position seems to be that persons who smoke cigarettes run a higher risk of chronic bronchitis than non-smokers and those who develop chronic bronchitis run a higher risk of developing lung cancer.

I am grateful to Professor M. R. Alderson, formerly director of the Regional Cancer Registration Bureau and the staff of the bureau for help and co-operation at every stage of this study. My thanks are also due to Miss B. Hepple and Mr. G. Robinson, of Mass Radiography Unit 13C, for careful searching and cross checking of the records. The Manchester Regional Hospital Board kindly allowed the use of their staff in the Mass Radiography Service, the computer section of the board's headquarters, and the registration bureau.

\section{References}

College of General Practitioners (1961), British Medical fournal, 2, 973. General Registrar Office (1968). Sample Census 1966. England and Wales: Migration Report, North Western Region. London, H.M.S.O.

Oswald, N. C., and Medvei, V. C. (1955). Lancet, 2, 843

Palmer, K. N. V. (1954). British Medical fournal, 1, 1473.

Rimington, J. (1968a). British Medical fournal, 1, 732.

Rimington, J. (1968b). British Medical fournal, 2, 492

Rimington, J. (1969). British fournal of Diseasesk of the Chest, 63, 193.

Todd, G. F. (editor) (1966). Statistics of Smonig in the United Kingdom, 4th edn. London, Tobacco Research Council.

\section{PRELIMINARY COMMUNICATIONS}

\section{Experimental Toxoplasmosis in Chimpanzees}

\author{
C. C. DRAPER, R. KILLICK-KENDRICK, \\ W. M. HUTCHISON, J. CHR. SIIM, \\ P. C. C. GARNHAM
}

British Medical fournal, 1971, 2, 375-378

\section{Summary}

Two chimpanzees were given by mouth large numbers of viable oocysts of Toxoplasma gondii obtained from the faeces of experimentally infected cats. Before the experiment the first chimpanzee had a positive dye test reaction (1:250), an indication that it had undergone an earlier infection of toxoplasmosis; the serum antibody titres remained unchanged, no evidence of illness was found, and oocysts did not appear in its faeces during the subsequent six weeks. The second chimpanzee showed a negative dye test reaction before infection, and this converted to positive on the 7 th day, rose to a peak on the 35th day, and remained high for six months. This animal appeared unwell during the first week, and on the 7th day its blood proved infective to mice; on the 40 th day the lymph nodes became enlarged and biopsy specimens of a node and muscle in the 11th week were also infective to mice. No oocysts were passed in the faeces. The presumed cycle in the

\footnotetext{
Ross Institute, London School of Hygiene and Tropical Medicine, London W.C.1.

C. C. DRAPER, D.M., Senior Lecturer

Department of Zoology and Applied Entomology, Imperial College, Ascot, Berks, SL5 7DE

R. KILLICK-KENDRICK, M.PHIL., Research Assistant

P. C. C. GARNHAM, C.M.G., M.D., F.R.S., Professor Emeritus

Department of Biology, University of Strathclyde, Glasgow C.1

W. M. HUTCHISON, B.Sc., PH.D., Senior Lecturer

Department of Toxoplasmosis and Viral Diseases, Statens Seruminstitut, Copenhagen, Denmark

J. CHR. SIIM, M.D., Director
}

chimpanzee and in man and the relationships between Toxoplasma and Isospora are discussed.

\section{Introduction}

Hutchison et al. (1970) elucidated the coccidian nature of Toxoplasma gondii by feeding specific pathogen-free cats with material infected with the cysts of this organism and observing typical stages of a coccidian parasite in the intestinal mucosa and faeces of the animals at various intervals after ingestion of the cysts. This work was confirmed by Sheffield and Melton (1970) and by Frenkel et al. (1970) in the United States, and by other workers in Germany, Holland, and Brazil. In all instances the cat was the experimental host and the infective forms were oocysts of a characteristic isosporan morphology (with two sporocysts each containing four elongated sporozoites).

Though toxoplasmosis is known to be transmitted in various ways, such as by placental passage, contamination of wounds, and consumption of infected uncooked meat, these new observations indicate that the natural biological cycle involves the swallowing of oocysts and the subsequent development of the parasite in the small intestine.

$T$. gondii is such a common human parasite that it is obviously important to determine the significance of these stages in the life history of the organism in natural infections in man. Though such infections are usually inapparent and rarely accompanied by disease it is clearly unjustifiable to use human volunteers to observe the reaction of man to the ingestion of oocysts. Accordingly, we fed oocysts to two chimpanzees, animals which are well known to exhibit a response to protozoan parasites similar to that shown by man, particularly if they have been previously splenectomized. Only two chimpanzees were available; it would have been better to have used a larger number but this was impracticable because of the high cost of these animals. Nevertheless, the results obtained suggest the sequence of events which may follow the ingestion of toxoplasma oocysts by man.

Our observations were directed to the following points: (1) clinical response, (2) passage of oocysts, (3) recovery of the organism in blood or tissues, (4) serological reaction, and (5) persistence of cysts in organs of animals after a long period (this work will be the subject of a later note.) 